\title{
Patients with osteoarthritis and avascular necrosis have better functional outcomes and those with avascular necrosis worse pain outcomes compared to rheumatoid arthritis after primary hip arthroplasty: a cohort study
}

\author{
Jasvinder A Singh ${ }^{1,2,3,4^{*}}$ and David G Lewallen ${ }^{3}$
}

\begin{abstract}
Background: This study was conducted to assess whether patient-reported outcomes (PROs) differ by the underlying diagnosis (rheumatoid arthritis (RA)/inflammatory arthritis, osteoarthritis (OA), avascular necrosis of bone $(\mathrm{AVN})$, other) in patients undergoing primary total hip arthroplasty (THA).

Methods: We used prospectively collected data to assess the association of diagnosis with index hip function and pain. Moderate-severe activity limitation and moderate-severe pain were assessed at two- and five-year follow-up after primary THA using multivariable-adjusted logistic regression analyses. Odds ratios (OR) and 95\% confidence intervals $(\mathrm{Cl})$ were calculated.

Results: There were 5,707 primary THAs at two-years and 3,289 at five-years, 51\% were women and the mean age was 65 years. The underlying diagnosis was RA in 3\%, OA in 87\%, AVN in 7\% and other in 3\%. In multivariableadjusted analyses, compared to RA, diagnoses of OA and AVN were significantly associated with lower odds of moderate-severe activities of daily living limitations with an OR $(95 \% \mathrm{Cl})$ of $0.5(0.3$ to 0.8$)(P=0.01)$ and $0.4(0.2$ to $0.8)(P=0.01)$, respectively, at two-years, but not at five-years, $0.7(0.4$ to 1.4$)(P=0.36)$ and 0.9 (0.4 to 1.8$)(P=0.78)$, respectively. At two-years, neither OA nor AVN were significantly associated with higher odds of moderate-severe pain (1.6 (0.6 to 4.5) $(P=0.40)$ and $2.8(0.9$ to 8.5$)(P=00.06))$, respectively. At five-years, AVN was associated with higher odds of moderate-severe pain with OR 4.1 (1.2 to 14.1) $(P=0.02)$, but not OA, 2.1 (0.7 to 6.5) $(P=0.22)$.

Conclusions: We found that patients with OA and AVN had better functional outcomes and those with AVN worse pain outcomes after primary THA, compared to patients with RA/inflammatory arthritis. Insights into mediators of these relationships are needed to better understand these associations.
\end{abstract}

Keywords: Total hip replacement, Diagnosis, Osteoarthritis, Rheumatoid arthritis, Avascular necrosis, Pain, Function, Arthroplasty, Joint replacement, Patient-reported outcomes, Risk factors

\footnotetext{
* Correspondence: Jasvinder.md@gmail.com

${ }^{1}$ Medicine Service and the Center for Surgical Medical Acute Care Research

and Transitions (C-SMART), Birmingham VA Medical Center, Birmingham,

AL, USA

${ }^{2}$ Department of Medicine at School of Medicine, and Division of

Epidemiology at School of Public Health, University of Alabama, Birmingham,

$\mathrm{AL}$, USA

Full list of author information is available at the end of the article
} 


\section{Background}

Total hip arthroplasty (THA) has been termed the operation of the century [1]. In patients with end-stage refractory hip arthritis or other hip problems, THA provides significant improvement in pain, function and quality of life $[2,3]$, which are the main reasons why patients undergo this procedure. A population-based study showed that the volume of THA is increasing rapidly with a significant increase in the last 10 years [4]; this increase is also reported in other landmark studies [5-7]. Previous studies have focused on surgical and implant factors affecting the risk of revision after THA. Although several studies have examined the factors associated with patient-reported outcomes (PROs) after THA, many fewer studies have examined the effect of underlying diagnosis on pain and functional outcomes post-THA. Most elective THAs are done for osteoarthritis (OA) or rheumatoid arthritis (RA) and a small proportion for avascular necrosis of bone (AVN; <5\%).

Do patients with OA have better PROs after primary THA compared to RA? The published literature is sparse and the answer unclear. In the largest of published studies, 381 patients were studied with two-year follow-up in 331 and five-year follow-up in 89 patients, pain and function (walking scores) at two years postTHA did not differ by the underlying diagnosis [8]. In other studies, compared to OA, RA was associated with worse functional outcomes at one year after THA [9], less pain and functional improvements at 2.5 years postarthroplasty in a study that combined patients with THA and total knee arthroplasty [10] and worse functional outcome at 10 years after THA (compared to historical controls) [11]. However, none of the studies with positive findings adjusted for important covariates and confounders, implying that they may potentially be false positive. Other major limitations of previous studies are that the follow-up was short and most had very few patients with RA. Therefore, it is unclear whether the underlying diagnosis is independently associated with outcomes after primary THA. Our objective was to assess the association of underlying diagnosis with pain and functional outcomes using a large total joint registry sample and adjusting for important covariates/confounders. We hypothesized that patients with OA as the underlying diagnosis will have better, and AVN worse, pain and functional outcomes after primary THA compared to patients with RA after adjusting for important covariates and confounders of pain and functional outcomes.

\section{Methods}

The methods and results are described as recommended in the Strengthening of Reporting in Observational studies in Epidemiology (STROBE) statement [12].

\section{Setting, participants and data sources}

For this study, we used the Mayo Total Joint Registry that prospectively collects data on all joint replacements performed at the Mayo Clinic, Rochester, MN, USA. Data in the registry include patient demographics, operative diagnosis, surgery and implant details, dates of evaluation, reoperations and complications, current radiographs and pain and functional assessments [13,14]. All patients who undergo THA at the Mayo Clinic are requested to complete a validated Mayo Hip questionnaire preoperatively and at two- and five-year follow-ups. The Mayo hip questionnaire has face, content and construct validity and test-retest reliability [15-17]. The pain and function questions are similar to those in the validated Harris Hip Score [18], the most widely used questionnaire in THA patients. The Mayo Hip questionnaires are mailed to the patients, administered during the clinic visit or by telephone by experienced, dedicated joint registry staff. Questionnaire data have been captured electronically starting in 1993. Patients were included in this study if they had undergone a primary THA from 1993 to 2005 and had responded to the Mayo hip survey at the two-year or five-year follow-up. Patients of all ages were included. The Institutional Review Board (IRB) at the Mayo Clinic, Rochester, MN, USA approved the study. Since it was a database study, the IRB waived the need for an informed consent.

\section{Predictors of interest and covariates}

The operative diagnosis was the main variable of interest, categorized as osteoarthritis (OA), rheumatoid or inflammatory arthritis (RA), avascular necrosis of bone $(\mathrm{AVN})$ and other. This was based on preoperative diagnosis (based on history, clinical examination, medications and the results of radiographic and other studies) as well as operative findings. We adjusted for covariates that included known and suspected correlates of pain and function after THA. Covariates were demographics (age, gender), body mass index (BMI), American Society of Anesthesiologist (ASA) class, distance from the medical center and implant fixation (uncemented, hybrid/ cemented) obtained from the Total Joint Registry and linked databases. Anxiety, depression and medical comorbidity using the validated Deyo-Charlson index [19] were based on the presence of International Classification of Diseases-ninth revision, common modification (ICD-9-CM) codes in the Mayo Clinic electronic databases, derived from administrative and clinical records. Distance from the medical center was included, since Mayo Clinic provides THA to local residents as well as referred patients traveling from far, who may have different disease severity and expectations, and both can impact pain and function outcomes [20-22]. In addition, we adjusted all functional outcome models for preoperative 
functional limitation assessed by preoperative limitation in seven activities of daily living (ADLs) and the pain models for preoperative pain severity, respectively.

\section{Outcomes of interest}

Study outcomes were PROs of moderate-severe ADL limitation and moderate-severe pain obtained from selfreported validated Mayo hip questionnaires at two years or five years (reference, no/mild categories) after THA. We defined these composite outcomes a priori as undesirable outcomes of THA as in previous studies [23,24], since THA is done primarily to relieve pain and improve function. Similar pain and ADL questions were also administered preoperatively; details are in Additional file 1: Table S1. For patients with multiple procedures, the latest observation for the index hip arthroplasty that was available prior to an additional procedure (and qualified for the two- or the five-year time point) was used as a conservative approach.

Patients self reported limitations in seven key ADLs that specifically assessed index hip function, including walking, climbing stairs, putting on shoes/socks, picking up objects from the floor, sitting in a chair, getting in/ out of the car and rising from a chair to a standing position. For four ADLs (walking, climbing stairs, sitting and rising from a chair), limitations were categorized into 'no', 'mild', 'moderate' or 'severe' limitation. The remaining three ADLs (putting on shoes/socks, picking up objects from the floor and getting in/out of the car), that did not have a response corresponding to the 'mild' category, were categorized into 'no', 'moderate' or 'severe' limitation, as previously [23]. The presence of three or more ADLs with moderate or severe limitation was classified as overall moderate to severe ADL limitation (reference, all other categories), as previously described [19].

Postoperative index hip pain was assessed with a single question on the hip questionnaire, namely 'Do you have pain in the hip in which the joint was replaced? no pain, slight, moderate, severe.' This validated question [15-17] is similar to the pain question in the Harris Hip Score, a commonly used THA outcome instrument that is valid, reliable and sensitive to change [25-27].

\section{Bias and sample size}

We tried to minimize confounding bias by including several covariates previously known or suspected to be associated with pain and ADL limitation after THA including the preoperative status, but recognize that residual confounding is a limitation of cohort study design. We accounted for correlation of observations (due to bilateral THA in patients, simultaneously or sequentially) using appropriate statistical methods. We anticipated non-response to be higher at five than at two years, and acknowledge this as a study limitation limiting the generalizability of results. We included a large enough sample to study pain and ADL limitation without having too long of a study period (to avoid significant secular trends in implants and procedure) and, therefore, chose all eligible patients from 1993 to 2005. No formal sample size calculations were done.

\section{Statistical analyses}

We used univariate and multivariable-adjusted logistic regression models to assess the association between the operative diagnosis and moderate-severe ADL limitation and moderate-severe pain two and five years after primary THA. The multivariable models included age, gender, BMI, ASA class, distance from the medical center, implant fixation, Deyo-Charlson index, anxiety and depression as well as respective preoperative variable/s preoperative pain for pain outcome and preoperative limitation in seven ADLs for ADL limitation outcome. Individual ADL limitations were only examined as exploratory analyses, to avoid multiple comparisons and results are presented in Additional file 1. Odds ratios (OR), 95\% confidence intervals (CI), and $P$-values are reported. Subgroup analyses were done for patients younger and older than 65 years to assess the association of diagnosis with pain and ADL outcomes, since patients with AVN or RA are expected to be younger than those with OA. We performed sensitivity analyses by restricting the study sample to surgery from 1998 to 2005, to examine whether change in RA management in the recent years impacted the noted associations in the main analyses.

All regression analyses used a generalized estimating equations (GEE) approach to adjust the standard errors for the correlation between observations on the same subject due to both hips having been replaced. Responder and non-responder characteristics were compared using logistic regression analyses, which were pre-specified to include demographics, comorbidity, implant-related factors and underlying diagnosis. We decided a priori not to impute any missing data and to treat them as missing. A $P$-value $<0.05$ was considered significant. Analyses were done using SPSS, version 21 (Chicago, IL, USA).

\section{IRB approval}

The Mayo Clinic Institutional Review Board approved this study and all investigations were conducted in conformity with ethical principles of research.

\section{Results}

Clinical and demographic characteristics are shown in Additional file 1: Table S2. A total of 5,707 patients provided data for the two-year and 3,289 for the five-year follow-up. For the two-year cohort, the mean age was 65 years, $51 \%$ were women, and $30 \%$ were $\leq 60$ years. BMI 
was $\geq 30 \mathrm{~kg} / \mathrm{m}^{2}$ in $76 \%$ of patients, and ASA score was class III/IV in $38 \%$. The underlying diagnosis was OA in $87 \%$, RA or inflammatory arthritis in $3 \%$ and AVN in $7 \%$ (3\%, other). Mean Deyo-Charlson score was 1 and depression and anxiety were present in $7 \%$ and $5 \%$, respectively. Characteristics were similar in the five-year cohort and also similar to patients who responded to the preoperative questionnaire [see Additional file 1: Table S2]. Baseline characteristics of the patients at 2-year follow-up according to their diagnosis are shown in Table 1 .

Table 1 Characteristics of patients with OA, RA, AVN and other diagnoses (2-year cohort)

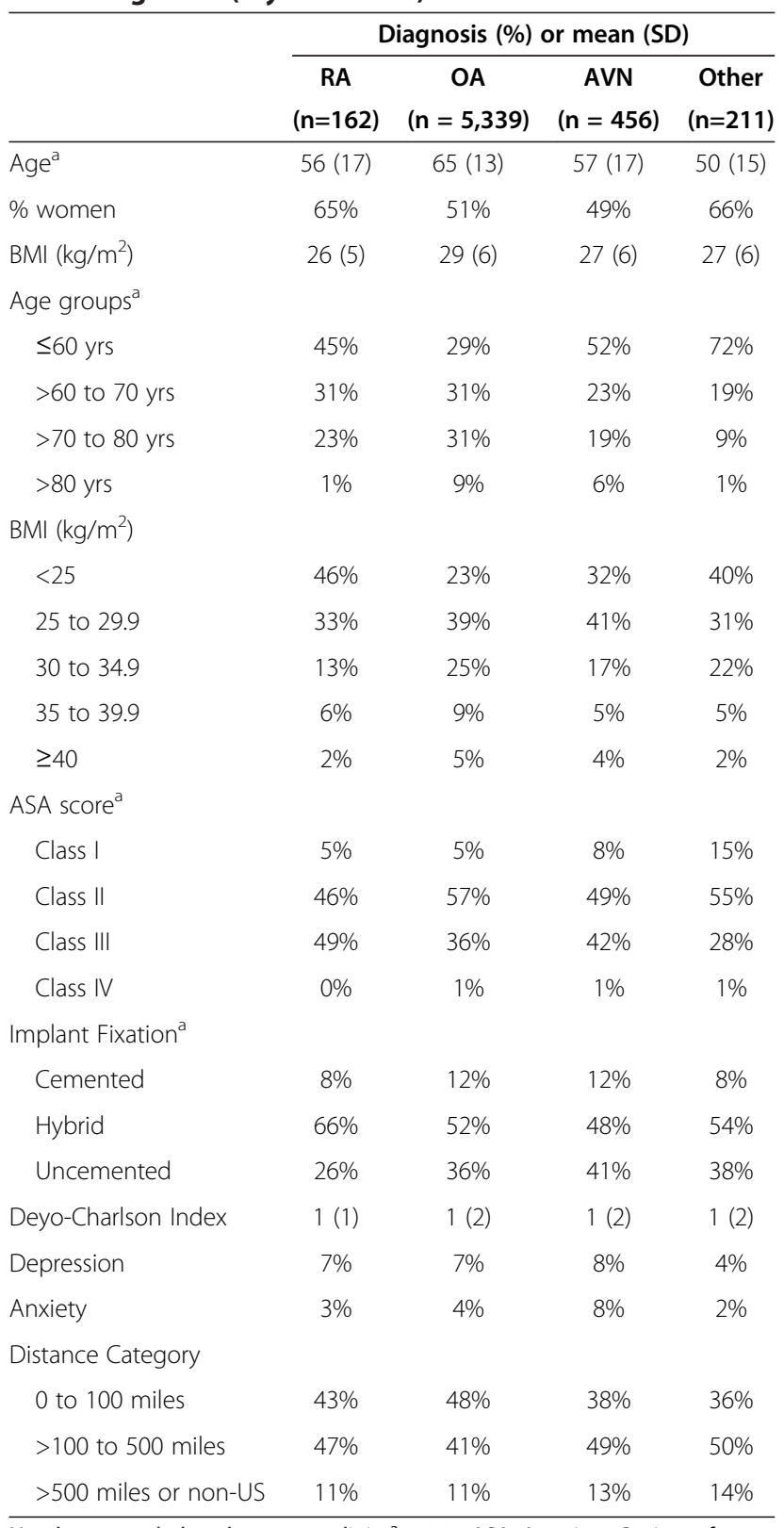

Numbers rounded to the nearest digit. ${ }^{\mathrm{a}} \mathrm{p}<0.05 \mathrm{ASA}$, American Society of Anesthesiologists; AVN, avascular necrosis of bone; BMI, body mass index; $O A$, osteoarthritis; RA, rheumatoid arthritis; SD, standard deviation.
Compared to patients with RA/inflammatory arthritis, those with OA were less likely to be women and more likely to be older or obese and those with AVN less likely to be women and more likely to be obese. There was little variation in the prevalence of moderate-severe pain $(91 \%$ to $95 \%$ ) and moderate-severe activity limitation (70\% to $80 \%$ ) by diagnosis preoperatively [see Additional file 1 : Table S3]. The survey response rates were 62\% (5,707/ $9,154)$ at the two-year and $53 \%(3,289 / 6,243)$ at the fiveyear follow-up.

\section{Responder characteristics}

Responders to the two-year post-primary THA survey were more likely to be older (age 61 to 70,71 to 80 and $>80$ with $\mathrm{ORs}=1.4,1.3$ and 1.3 , respectively, compared to $\leq 60$ years) and less likely to have BMI $\geq 40$ (OR, 0.7), ASA class III-IV $(\mathrm{OR}, 0.9)$ or live further from the medical center (distance $>100$ to 500, OR, 0.9; and $>500$ miles with OR, 0.7) (Table 2). At five years, responders were more likely to be older (age 61 to 70 with OR, 1.4; 71 to 80 with OR, 1.4), have a BMI $=25$ to 29.9 (OR, 1.2 ), and less likely to live further from the medical center (distance $>100$ to 500 with $\mathrm{OR}=0.9$ and $>500$ miles with $\mathrm{OR}=0.6)$.

\section{Univariate association of diagnosis with pain and overall activity limitation}

In unadjusted analyses, we noted that compared to RA/ inflammatory arthritis, the odds of overall moderatesevere ADL limitation at two years were significantly lower in OA and AVN patients (Table 3). On the other hand, compared to RA/ inflammatory arthritis, the odds of moderate-severe pain at two years were significantly higher in patients with OA (Table 3). Similar findings were noted at 5-years, except that moderate-severe pain associations at 5 -years were only borderline significant $(P=0.07)$.

\section{Multivariable-adjusted association of diagnosis with overall activity limitation and pain}

In adjusted analyses, compared to patients with RA/ inflammatory arthritis, those with OA and AVN had significantly lower odds of overall moderate-severe ADL limitation at two years (Table 4). No differences by diagnosis were noted in moderate-severe pain at two years. Compared to patients with RA, patients with AVN and other diagnosis had significantly higher odds of moderatesevere pain at five years, but no significant differences in moderate-severe ADL limitation at five years (Table 4).

Sensitivity analyses performed by restricting the analyses to the time period of surgery to 1998 to 2005 revealed minimal change in ORs and no change in significance for association of OA or AVN with moderate-severe activity limitations at two years, with ORs of 0.4 ( $95 \%$ CI, 0.2 
Table 2 Characteristics of responders to Mayo Hip Questionnaire (pain and functional limitation) for primary THA

\begin{tabular}{|c|c|c|c|c|c|c|}
\hline \multirow[b]{2}{*}{ Variable } & \multicolumn{3}{|c|}{ Two years } & \multicolumn{3}{|c|}{ Five years } \\
\hline & Events for responders & $\begin{array}{l}\text { Odds ratio } \\
(95 \% \mathrm{Cl})\end{array}$ & $\overline{P \text {-value }}$ & Events for responders & $\begin{array}{l}\text { Odds ratio } \\
(95 \% \mathrm{Cl})\end{array}$ & $P$-value \\
\hline \multicolumn{7}{|l|}{ Gender } \\
\hline Female & 1976/4736 (41.7\%) & & & $1244 / 3281(37.9 \%)$ & & \\
\hline Male & $1847 / 4418$ (41.8\%) & $1.0(0.9$ to 1.1$)$ & 0.94 & $1130 / 2962(38.1 \%)$ & $1.0(0.9$ to 1.1$)$ & 0.85 \\
\hline \multicolumn{7}{|l|}{ Age Category } \\
\hline$<60$ & $1176 / 2988$ (39.4\%) & & & $737 / 2075(35.5 \%)$ & & \\
\hline 61 to 70 & $1204 / 2676(45 \%)$ & $1.3(1.1$ to 1.4$)$ & $<0.01$ & 791/1893 (41.8\%) & $1.3(1.1$ to 1.5$)$ & $<.01$ \\
\hline 71 to 80 & $1121 / 2706$ (41.4\%) & 1.1 (1.0 to 1.2$)$ & 0.12 & 706/1841 (38.3\%) & 1.1 (1.0 to 1.3$)$ & 0.08 \\
\hline$>80$ & $322 / 784(41.1 \%)$ & $1.1(0.9$ to 1.3$)$ & 0.40 & $140 / 434(32.3 \%)$ & $0.9(0.7$ to 1.1$)$ & 0.20 \\
\hline \multicolumn{7}{|l|}{ BMI Category } \\
\hline$<25$ & 935/2221 (42.1\%) & & & $571 / 1570(36.4 \%)$ & & \\
\hline 25 to 29.9 & $1493 / 3477(42.9 \%)$ & 1.0 (0.9 to 1.2$)$ & 0.54 & 954/2393 (39.9\%) & $1.2(1.0$ to 1.3$)$ & 0.03 \\
\hline 30 to 34.9 & $907 / 2209(41.1 \%)$ & $1.0(0.8$ to 1.1$)$ & 0.49 & $548 / 1479(37.1 \%)$ & $1.0(0.9$ to 1.2$)$ & 0.70 \\
\hline 35 to 39.9 & 309/786 (39.3\%) & $0.9(0.8$ to 1.1$)$ & 0.19 & 187/515 (36.3\%) & 1.0 (0.8 to 1.2$)$ & 0.98 \\
\hline$>40$ & $161 / 419$ (38.4\%) & $0.9(0.7$ to 1.1$)$ & 0.17 & 102/259 (39.4\%) & 1.1 (0.9 to 1.5$)$ & 0.38 \\
\hline \multicolumn{7}{|l|}{ ASA Score } \\
\hline 1 to 2 & $2410 / 5608(43 \%)$ & & & $1539 / 3950(39 \%)$ & & \\
\hline 3 to 4 & 1396/3509 (39.8\%) & 0.9 (0.8 to 1.0$)$ & $<0.01$ & $823 / 2261(36.4 \%)$ & 0.9 (0.8 to 1.0$)$ & 0.05 \\
\hline Charlson Index (5 point increase) & N/A & 0.8 (0.7 to 0.9$)$ & & N/A & $0.9(0.7$ to 1.0$)$ & 0.05 \\
\hline \multicolumn{7}{|l|}{ Distance Category } \\
\hline 0 to 100 miles & $1785 / 4145(43.1 \%)$ & & & $1093 / 2743(39.8 \%)$ & & \\
\hline$>100$ to 500 miles & $1531 / 3695(41.4 \%)$ & $0.9(0.9$ to 1.0$)$ & 0.16 & $935 / 2520(37.1 \%)$ & $0.9(0.8$ to 1.0$)$ & 0.05 \\
\hline$>500$ miles or non-US & $381 / 988(38.6 \%)$ & $0.8(0.7$ to 1.0$)$ & 0.01 & $220 / 675(32.6 \%)$ & $0.7(0.6$ to 0.9$)$ & $<0.01$ \\
\hline \multicolumn{7}{|l|}{ Operative Diagnosis } \\
\hline Inflammatory arthritis & $94 / 251(37.5 \%)$ & & & $71 / 205(34.6 \%)$ & & \\
\hline AVN & $257 / 687(37.4 \%)$ & $1.0(0.7$ to 1.4$)$ & 0.99 & $176 / 519(33.9 \%)$ & $1.0(0.7$ to 1.4$)$ & 0.86 \\
\hline Osteoarthritis & $3355 / 7825$ (42.9\%) & $1.3(1.0$ to 1.6$)$ & 0.10 & 2030/5218 (38.9\%) & $1.2(0.9$ to 1.6$)$ & 0.23 \\
\hline Other & $117 / 391(29.9 \%)$ & $0.7(0.5$ to 1.0$)$ & 0.05 & $97 / 301(32.2 \%)$ & $0.9(0.6$ to 1.3$)$ & 0.59 \\
\hline
\end{tabular}

ASA, American Society of Anesthesiologists; AVN, avascular necrosis of bone; BMI, body mass index; Cl, confidence interval; THA, total hip arthroplasty.

to 0.8 ) and 0.4 (95\% CI, 0.2 to 0.8$)$, respectively. The OR of association of diagnosis with moderate-severe pain at five years and the level of significance showed minimal change.

Subgroup analyses for patients $<65$ and those 65 years and older showed that ORs noted in the main analyses changed little: OA and AVN patients younger than 65 years had lower odds of moderate-severe ADL limitation at two years (0.4 (95\% CI 0.2 to 0.9$), P=0.03)$, and 0.5 (0.2 to 1.0$)$, $P=0.06)$ just as those 65 years and older did $(0.4$ (95\% CI 0.2 to 0.9$), P=0.03$ and 0.4 (0.2 to 0.8$), P=0.008$ ).

\section{Exploratory univariate and multivariable-adjusted} analyses of limitation in seven activities In univariate analyses, we found that compared to those with RA/inflammatory arthritis, patients with OA had significantly lower odds of moderate-severe limitations in walking, climbing stairs, putting on socks/shoes, picking up objects and rising from a chair at two years post-primary THA (Table 5). At five years, results were similar except that differences were not significant for walking and rising from a chair. Similarly, compared to those with RA/inflammatory arthritis, patients with AVN were significantly less likely to have limitations in climbing stairs, putting on socks/shoes, picking up objects and rising from a chair at two years (Table 6); results were similar at five years (Table 6).

In multivariable-adjusted analyses, patients with $\mathrm{OA}$ had significantly lower odds of limitation in rising from a chair at two years (Table 6). Patients with AVN had significantly lower odds of limitation in putting on shoes/socks or rising from a chair at two years (Table 6). 
Table 3 Univariate association of diagnosis with ADL limitation and pain at two and five years after primary THA

\begin{tabular}{|c|c|c|c|c|}
\hline & & Diagnosi & & \\
\hline & $\mathrm{RA} /$ inflammatory arthritis & $O A$ & AVN & Other \\
\hline Overall moderate-severe ADL limit & & & & \\
\hline Two-year follow-up & $67 / 140(47.9 \%)$ & $1384 / 4714(29.4 \%)$ & $115 / 389(29.6 \%)$ & 83/192 (43.2\%) \\
\hline$P$-value compared to RA group & & $<0.01$ & $<0.01$ & 0.43 \\
\hline Five-year follow-up & 45/97 (46.4\%) & $911 / 2648(34.4 \%)$ & 77/246 (31.3\%) & $62 / 139(44.6 \%)$ \\
\hline$P$-value compared to RA group & & 0.01 & 0.02 & 0.79 \\
\hline Moderate-severe hip pain & & & & \\
\hline Two-year follow-up & $7 / 142(4.9 \%)$ & $355 / 4676(7.6 \%)$ & 47/378 (12.4\%) & 26/194 (13.4\%) \\
\hline$P$-value compared to RA group & & 0.02 & 0.24 & 0.01 \\
\hline Five-year follow-up & $7 / 93(7.5 \%)$ & 270/2651 (10.2\%) & $37 / 244(15.2 \%)$ & 25/142 (17.6\%) \\
\hline$P$-value compared to RA group & & 0.07 & 0.41 & 0.03 \\
\hline
\end{tabular}

Reference category is rheumatoid arthritis/inflammatory arthritis and $P$-values were obtained from univariate logistic regression models. Numbers in bold represents significant p-value $<\mathbf{0 . 0 5}$. $A D L$, activities of daily living; $A V N$, avascular necrosis of bone; OA, osteoarthritis; RA, rheumatoid arthritis; $T H A$, total hip arthroplasty.

Compared to patients with RA, patients with AVN and OA had significantly lower odds of limitation in climbing stairs at five years.

\section{Discussion}

In this prospective study of a large cohort of patients with primary THA, we found that after adjusting for important predictors, patients with OA had significantly better functional outcomes compared to those with RA/ inflammatory arthritis at two-year follow-up. Results were notable for overall ADL limitation and key ADLs. Pain outcomes were not significantly different for OA versus RA. We also found that patients with AVN experienced better ADL outcome at two years compared to RA patients. In contrast, patients with AVN reported worse pain outcomes at five years compared to those with RA. Several findings in our study are of interest and merit further discussion.
One of the main findings of our study was that patients with OA had significantly better functional outcomes compared to those with RA at the two-year follow-up, as indicated by lower odds of overall moderate-severe ADL limitation. These findings were confirmed for patients younger and older than 65 years. To our knowledge, this is the first study to have analyzed the association of diagnosis with functional outcomes adjusted for known correlates of outcome in a large sample of patients at both the two- and five-year follow-up after primary THA. On the other hand, we found no significant differences in risk of moderate-severe pain between $\mathrm{OA}$ and RA in multivariable-adjusted models. The greater ADL limitation noted in RA patients compared to OA patients may be due to the systemic inflammatory processes in RA versus OA [28], a higher risk of postoperative dislocation after primary THA in RA versus OA patients [29], and/or a more polyarticular disease in RA compared to OA. As stated previously, 'A single THR (total hip replacement)

Table 4 Multivariable-adjusted association of diagnosis with ADL limitation and pain at two and five years after primary THA

\begin{tabular}{|c|c|c|c|c|c|c|}
\hline & \multicolumn{2}{|c|}{ OA } & \multicolumn{2}{|c|}{ AVN } & \multicolumn{2}{|c|}{ Other } \\
\hline & $\mathrm{OR}^{\mathrm{a}}(95 \% \mathrm{Cl})$ & $P$-value & $\mathrm{OR}^{\mathrm{a}}(95 \% \mathrm{Cl})$ & $P$-value & $\mathrm{OR}^{\mathrm{a}}(95 \% \mathrm{Cl})$ & $P$-value \\
\hline \multicolumn{7}{|c|}{ Moderate-severe overall ADL limitation ${ }^{\mathrm{b}}$} \\
\hline Two-years & $0.5(0.3,0.8)$ & 0.01 & $0.4(0.2$ to 0.8$)$ & 0.01 & $1.0(0.5$ to 1.9$)$ & 0.91 \\
\hline Five-years & 0.7 (0.4 to 1.4$)$ & 0.36 & 0.9 (0.4 to 1.8$)$ & 0.78 & 2.1 (0.9 to 4.8$)$ & 0.07 \\
\hline \multicolumn{7}{|c|}{ Moderate-severe hip pain ${ }^{c}$} \\
\hline Two-years & $1.6(0.6$ to 4.5$)$ & 0.40 & 2.8 (0.9 to 8.5$)$ & 0.06 & $2.2(0.6$ to 7.3$)$ & 0.22 \\
\hline Five-years & $2.1(0.7$ to 6.5$)$ & 0.22 & $4.1(1.2$ to 14.1$)$ & 0.02 & $4.2(1.1$ to 16.0$)$ & 0.04 \\
\hline
\end{tabular}

${ }^{a}$ Reference category is rheumatoid arthritis/inflammatory arthritis; ${ }^{b}$ adjusted for 16 additional covariates/confounders: age, gender, BMI, Deyo-Charlson comorbidity score, ASA class, distance from the medical center, cement fixation, preoperative limitation in seven activities, anxiety and depression; ' $a d j u s t e d$ for 10 additional covariates/confounders: age, gender, BMI, Deyo-Charlson comorbidity score, ASA class, distance from the medical center, cement fixation, preoperative pain, anxiety and depression. Numbers in bold represents significant p-value $<\mathbf{0 . 0 5}$. ADL, activities of daily living; ASA, American Society of Anesthesiologists; AVN, avascular necrosis of bone; BMI, body mass index; Cl, confidence interval; OA, osteoarthritis; OR, odds ratio; RA, rheumatoid arthritis; THA, total hip arthroplasty. 
Table 5 Univariate association of diagnosis with each ADL limitation at two and five years after primary THA

\begin{tabular}{|c|c|c|c|c|c|c|c|c|}
\hline & \multirow[b]{2}{*}{ n/N (\%) } & \multicolumn{3}{|c|}{ Two years } & \multirow[b]{2}{*}{ n/N (\%) } & \multicolumn{3}{|c|}{ Five years } \\
\hline & & $\mathrm{OR}^{\mathrm{a}}$ & $95 \% \mathrm{Cl}$ & $P$-value & & $\mathrm{OR}^{\mathrm{a}}$ & $95 \% \mathrm{Cl}$ & $P$-value \\
\hline \multicolumn{9}{|c|}{ Limitations in walking } \\
\hline $\mathrm{RA}^{\mathrm{a}}$ & $50 / 141(35.5 \%)$ & 1.0 (ref) & & & $38 / 97(39.2 \%)$ & 1.0 (ref) & & \\
\hline Osteoarthritis & $1298 / 4815(27 \%)$ & 0.7 & $(0.5$ to 1.0$)$ & 0.04 & $927 / 2723(34 \%)$ & 0.8 & (0.5 to 1.2$)$ & 0.32 \\
\hline AVN & $113 / 397(28.5 \%)$ & 0.7 & $(0.5$ to 1.1$)$ & 0.15 & $74 / 250(29.6 \%)$ & 0.7 & $(0.4$ to 1.1$)$ & 0.10 \\
\hline Other & 70/201 (34.8\%) & 1.0 & (0.6 to 1.6$)$ & 0.91 & $51 / 145(35.2 \%)$ & 0.8 & $(0.5$ to 1.5$)$ & 0.55 \\
\hline \multicolumn{9}{|c|}{ Limitations in climbing stairs } \\
\hline RA & $53 / 144(36.8 \%)$ & 1.0 (ref) & & & $38 / 98(38.8 \%)$ & 1.0 (ref) & & \\
\hline Osteoarthritis & $818 / 4873(16.8 \%)$ & 0.3 & $(0.2$ to 0.5$)$ & $<0.01$ & $562 / 2739(20.5 \%)$ & 0.4 & $(0.3$ to 0.6$)$ & $<0.01$ \\
\hline AVN & 77/397 (19.4\%) & 0.4 & $(0.3$ to 0.6$)$ & $<0.01$ & $48 / 250(19.2 \%)$ & 0.4 & $(0.2$ to 0.6$)$ & $<0.01$ \\
\hline Other & $55 / 202(27.2 \%)$ & 0.6 & (0.4 to 1.0$)$ & 0.07 & $43 / 145(29.7 \%)$ & 0.7 & $(0.4$ to 1.2$)$ & 0.15 \\
\hline \multicolumn{9}{|c|}{ Limitations in putting on socks/shoes } \\
\hline RA & $57 / 143(39.9 \%)$ & 1.0 (ref) & & & $37 / 97(38.1 \%)$ & 1.0 (ref) & & \\
\hline Osteoarthritis & $1178 / 4867$ (24.2\%) & 0.5 & $(0.3$ to 0.7$)$ & $<0.01$ & $725 / 2733(26.5 \%)$ & 0.6 & (0.4 to 0.9$)$ & 0.02 \\
\hline AVN & $85 / 400(21.3 \%)$ & 0.4 & $(0.3$ to 0.6$)$ & $<0.01$ & $68 / 253(26.9 \%)$ & 0.6 & $(0.4$ to 1.0$)$ & 0.05 \\
\hline Other & $74 / 201(36.8 \%)$ & 0.9 & (0.6 to 1.4$)$ & 0.59 & $54 / 144(37.5 \%)$ & 1.0 & $(0.6$ to 1.7$)$ & 0.92 \\
\hline \multicolumn{9}{|c|}{ Limitations in picking up objects } \\
\hline RA & $55 / 145(37.9 \%)$ & 1.0 (ref) & & & $40 / 98(40.8 \%)$ & 1.0 (ref) & & \\
\hline Osteoarthritis & $1153 / 4873$ (23.7\%) & 0.5 & $(0.4$ to 0.7$)$ & $<0.01$ & $730 / 2735(26.7 \%)$ & 0.5 & $(0.3$ to 0.8$)$ & $<0.01$ \\
\hline AVN & $92 / 399(23.1 \%)$ & 0.5 & $(0.3$ to 0.7$)$ & $<0.01$ & $63 / 252(25 \%)$ & 0.5 & $(0.3$ to 0.8$)$ & $<0.01$ \\
\hline Other & $68 / 203(33.5 \%)$ & 0.8 & (0.5 to 1.3$)$ & 0.41 & $50 / 146(34.2 \%)$ & 0.8 & (0.4 to 1.3$)$ & 0.32 \\
\hline \multicolumn{9}{|c|}{ Limitations in getting in/out of car } \\
\hline RA & 29/144 (20.1\%) & 1.0 (ref) & & & $21 / 98(21.4 \%)$ & 1.0 (ref) & & \\
\hline Osteoarthritis & 703/4864 (14.5\%) & 0.7 & (0.4 to 1.0$)$ & 0.06 & $488 / 2745(17.8 \%)$ & 0.8 & (0.5 to 1.3$)$ & 0.39 \\
\hline AVN & $63 / 401(15.7 \%)$ & 0.7 & (0.4 to 1.2$)$ & 0.24 & $40 / 251(15.9 \%)$ & 0.7 & (0.4 to 1.3$)$ & 0.26 \\
\hline Other & 48/202 (23.8\%) & 1.2 & (0.7 to 2.1$)$ & 0.43 & $36 / 146(24.7 \%)$ & 1.2 & (0.6 to 2.3$)$ & 0.58 \\
\hline \multicolumn{9}{|c|}{ Limitations in rising from chair } \\
\hline RA & 25/144 (17.4\%) & 1.0 (ref) & & & 14/98 (14.3\%) & 1.0 (ref) & & \\
\hline Osteoarthritis & $353 / 4852(7.3 \%)$ & 0.4 & $(0.2$ to 0.6$)$ & $<0.01$ & $272 / 2727(10 \%)$ & 0.7 & (0.4 to 1.2$)$ & 0.17 \\
\hline AVN & $39 / 401$ (9.7\%) & 0.5 & $(0.3$ to 0.9$)$ & 0.02 & $30 / 252(11.9 \%)$ & 0.8 & (0.4 to 1.6$)$ & 0.55 \\
\hline Other & 24/201 (11.9\%) & 0.6 & (0.4 to 1.2$)$ & 0.16 & 18/143 (12.6\%) & 0.9 & (0.4 to 1.8$)$ & 0.70 \\
\hline \multicolumn{9}{|c|}{ Limitations in sitting } \\
\hline RA & $1 / 143(0.7 \%)$ & 1.0 (ref) & & & 1/97 (1\%) & 1.0 (ref) & & \\
\hline Osteoarthritis & $44 / 4850(0.9 \%)$ & 1.3 & (0.2 to 9.5$)$ & 0.8 & $26 / 2724(1 \%)$ & 0.9 & (0.1 to 6.9$)$ & 0.94 \\
\hline AVN & 9/396 (2.3\%) & 3.3 & (0.4 to 26.3 ) & 0.3 & $7 / 251(2.8 \%)$ & 2.8 & (0.3 to 22.7 ) & 0.35 \\
\hline Other & $2 / 200(1.0 \%)$ & 1.4 & (0.1 to 16.0$)$ & 0.8 & 3/144 (2.1\%) & 2.0 & (0.2 to 20.0$)$ & 0.54 \\
\hline
\end{tabular}

${ }^{a}$ Reference category is rheumatoid arthritis/inflammatory arthritis. --, not applicable, since these ADLs did not have a response for mild limitation category. Numbers in bold represents significant p-value $<\mathbf{0 . 0 5}, A D L$, activities of daily living; $A V N$, avascular necrosis of bone; $\mathrm{Cl}$, confidence interval; $\mathrm{OR}$, odds ratio; $\mathrm{RA}$, rheumatoid arthritis; THA, total hip arthroplasty.

apparently solves the main problem of most OA patients, but only one of a number of joint problems for most RA patients' [9]. It is important to note that in exploratory analyses, several associations for key ADLs that were significant in univariate models were no longer significant in multivariable-adjusted models, indicating that these associations were not independent of the covariates adjusted in the multivariable analyses. However, results were significant for rising from a chair and climbing stairs in multivariable-adjusted models.

Previous studies that have examined functional outcomes in THA patients have reported contradictory 
Table 6 Multivariable-adjusted association of diagnosis with each ADL limitation at two and five years after primary THA

\begin{tabular}{|c|c|c|c|c|c|c|}
\hline & \multicolumn{3}{|c|}{ Two years } & \multicolumn{3}{|c|}{ Five years } \\
\hline & $\overline{\mathrm{OR}^{\mathrm{a}}}$ & $95 \% \mathrm{Cl}$ & $P$-value & $\overline{\mathrm{OR}^{\mathrm{a}}}$ & $95 \% \mathrm{Cl}$ & $P$-value \\
\hline \multicolumn{7}{|c|}{ Limitations in walking $^{\mathrm{b}}$} \\
\hline Osteoarthritis & 0.7 & $(0.4,1.2)$ & 0.21 & 0.8 & $(0.4,1.5)$ & 0.43 \\
\hline AVN & 0.8 & $(0.4,1.7)$ & 0.63 & 0.8 & $(0.4,1.8)$ & 0.62 \\
\hline Other & 1.3 & $(0.6,2.7)$ & 0.55 & 1.2 & $(0.5,3.1)$ & 0.67 \\
\hline \multicolumn{7}{|c|}{ Limitations in climbing stairs ${ }^{b}$} \\
\hline Osteoarthritis & 0.6 & $(0.3,1.0)$ & 0.07 & 0.5 & $(0.3,0.9)$ & 0.03 \\
\hline AVN & 0.5 & $(0.3,1.1)$ & 0.07 & 0.5 & $(0.2,1.0)$ & 0.049 \\
\hline Other & 1.0 & $(0.5,2.1)$ & 0.95 & 0.9 & $(0.4,2.2)$ & 0.80 \\
\hline \multicolumn{7}{|c|}{ Limitations in putting on socks/shoes ${ }^{b}$} \\
\hline Osteoarthritis & 0.7 & $(0.4,1.1)$ & 0.12 & 0.7 & $(0.4,1.3)$ & 0.27 \\
\hline AVN & 0.5 & $(0.3,0.9)$ & 0.03 & 0.9 & $(0.4,1.8)$ & 0.72 \\
\hline Other & 1.6 & $(0.8,3.2)$ & 0.16 & 2.0 & $(1.0,4.4)$ & 0.07 \\
\hline \multicolumn{7}{|c|}{ Limitations in picking up objects ${ }^{\mathrm{b}}$} \\
\hline Osteoarthritis & 0.7 & $(0.4,1.1)$ & 0.10 & 0.6 & $(0.3,1.1)$ & 0.09 \\
\hline AVN & 0.6 & $(0.3,1.1)$ & 0.08 & 0.8 & $(0.4,1.6)$ & 0.50 \\
\hline Other & 1.1 & $(0.6,2.3)$ & 0.73 & 1.5 & $(0.7,3.3)$ & 0.30 \\
\hline \multicolumn{7}{|c|}{ Limitations in getting in/out of car ${ }^{b}$} \\
\hline Osteoarthritis & 1.0 & $(0.5,2.0)$ & 0.98 & 0.8 & $(0.4,1.6)$ & 0.53 \\
\hline AVN & 0.9 & $(0.4,2.0)$ & 0.78 & 0.9 & $(0.4,2.1)$ & 0.84 \\
\hline Other & 1.1 & $(0.4,2.9)$ & 0.80 & 1.5 & $(0.6,3.7)$ & 0.36 \\
\hline \multicolumn{7}{|c|}{ Limitations in rising from chair ${ }^{b}$} \\
\hline Osteoarthritis & 0.4 & $(0.2,0.9)$ & 0.03 & 1.0 & $(0.4,2.5)$ & 0.99 \\
\hline AVN & 0.4 & $(0.2,0.9)$ & 0.04 & 1.3 & $(0.4,3.8)$ & 0.66 \\
\hline Other & 0.7 & $(0.3,2.2)$ & 0.59 & 1.4 & $(0.4,4.9)$ & 0.56 \\
\hline \multicolumn{7}{|c|}{ Limitations in sitting ${ }^{b}$} \\
\hline Osteoarthritis & N/A & & & N/A & & \\
\hline \multicolumn{7}{|l|}{ AVN } \\
\hline Other & & & & & & \\
\hline
\end{tabular}

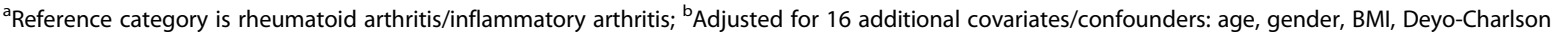
comorbidity score, ASA class, distance from the medical center, cement fixation, preoperative limitation in seven activities, anxiety and depression; N/A, not applicable, since the model did not run for sitting, due to too few cases. ADL, activities of daily living; ASA, American Society of Anesthesiologists; AVN, avascular necrosis of bone; $\mathrm{BMI}$, body mass index; $\mathrm{Cl}$, confidence interval; OR, odds ratio; RA, rheumatoid arthritis; THA, total hip arthroplasty.

findings. In a study of 381 patients, pain and function (walking scores) at two years post-THA did not differ by the underlying diagnosis [8]. On the other hand, some studies have reported worse outcomes in patients with RA compared to OA. In their study of 97 patients, Borstlap et al. reported that patients with OA experienced better functional outcomes one year after THA compared to those with RA [9]. A study of 106 RA patients by Creighton et al. suggested that RA was associated with less optimal functional improvement at 10 years as compared to other diagnoses (OA, and so on) in their other studies [11]. Kirwan et al. studied 293 patients who underwent total hip or total knee replacement at 2.5 years and found greater improvements in pain and function in OA compared to RA [10]. Hawker et al. examined the predictors of successful joint arthroplasty outcome in a cohort of 233 patients with either hip or knee joint replacement and found that RA was associated with 0.33 odds of good outcome compared to OA, based on WOMAC total score improvements, a pain and function composite [30]. Two of the four positive studies combined knee and hip arthroplasty patients, and studies show that outcomes from these two procedures differ [31], as do the 
underlying diagnoses [32,33], which makes the interpretation of these studies difficult for THA populations. Previous studies had small sample sizes, heterogeneous populations, unadjusted analyses, historical controls and contradictory findings. Our findings from a multivariable-adjusted analysis from a large total joint registry provide clarity and add to the current knowledge. Our findings suggest that functional outcomes were better in OA versus RA and that there were no significant differences in pain outcomes two years and five years after THA.

Another important study finding was the lack of difference in pain outcomes in RA versus OA patients after THA. This is reassuring given that the most common symptom leading to THA is severe, refractory hip joint pain. This implies that patients with RA can be reassured that their pain outcomes will be similar to the majority of patients with OA undergoing THA.

Another interesting finding from our study is that patients with AVN were less likely to have moderatesevere ADL limitations and more likely to report moderate-severe pain compared to patients with RA. To our knowledge, this is a new finding and adds to the literature. A recent systematic review of outcomes of THA in patients with $\mathrm{AVN}$ found that most studies had a low evidence level of III and IV and provided data only related to revision rates [34], indicating a lack of studies of PROs in this patient population. Our finding of worse pain outcomes in AVN patients compared to RA patients might indicate the difference in pathophysiology of the two conditions (AVN versus RA) and polyarticular and bilateral involvement with RA [9] compared to AVN. In addition, documented high rates of early complications and reoperations in AVN patients (17\% and 11\%, respectively, at an average follow-up of 20 months) [35] may also explain better ADL outcomes in AVN versus RA.

The practical implications of our study are several-fold. First our study highlights the importance of studying both pain and functional outcomes in arthroplasty patients, as discussed previously [36]. Although these domains are somewhat interrelated, they can be discordant due to different slopes of recovery post-arthroplasty; for example, at three months post-THA, patients are likely to report significant improvement in pain, but function may be the same as it was preoperatively due to continuing recovery and rehabilitation. Similarly, other lower extremity joint involvement and back problems impact pain and function differently, that is, the impact on function may be tremendous, but there may be no impact on index hip pain. Our study further demonstrates that the underlying diagnosis impacts pain and function after primary THA differently. This new information can help surgeons inform their patients preoperatively during the informed consent process with regard to expected outcomes after primary THA, based on their underlying diagnosis. Given the longevity of the implant and the elective nature of the surgery, a better insight into why certain diagnoses are associated with worse outcome can help to improve these outcomes even further, if modifiable intermediate factors can be identified. This will also lead to even more informed patients and reduction of unsatisfactory outcome after primary THA, a highly successful surgery.

Our study has several limitations and strengths. Survey non-response may have introduced some bias, and the direction of this bias is unclear. Our response rates are similar to the average $60 \%$ response rate reported for large surveys of this size [37]; however, the five-year estimates should be interpreted with caution. Due to a cohort study design, residual confounding is possible, despite inclusion of multiple clinical and demographic variables. There may be some misclassification of operative diagnosis due to similarity of gross findings at surgery between RA and AVN and because classification criteria are not used in clinical orthopedic practice for RA and are not available for AVN. However, the surgeon incorporates history, examination and medication use in making the diagnosis that should provide good accuracy. Misclassification bias may have biased our results towards null. Generalizability is always a challenge, but the similarity of our cohort to other hip arthroplasty cohorts indicates that results may be generalizable to other settings $[6,7,38]$. Study strengths include a follow-up at two time-points, large sample size to allow adequate power, prospective data collection by dedicated Total Joint Registry staff and multivariable-adjusted analyses that adjusted for other factors known/likely to be associated with the outcomes.

\section{Conclusions}

Our study is among the first well-powered studies adjusted for important covariates and confounders that showed that the underlying diagnosis for primary THA is a significant predictor of functional outcomes and pain up to five years post-THA. We found that compared to RA, OA was associated with better overall functional outcome after primary THA. Compared to RA, AVN was associated with better overall functional and worse pain outcomes after primary THA. Future studies need to investigate the underlying pathophysiology and reasons for these significant findings, which can help us understand better the true mechanism of pain and functional outcomes after primary THA.

\section{Additional file}

Additional file 1: Table S1. Study outcomes definition. Table S2. Demographic and clinical characteristics of Primary THA cohort. Table S3. Moderate severe functional limitation by diagnosis at three time-points. 


\section{Abbreviations}

ADL: Activities of daily living; ASA: American Society of Anesthesiologists; AVN: Avascular necrosis of bone; BMI: Body mass index; Cl: Confidence interval; OA: Osteoarthritis; RA: Rheumatoid arthritis; OR: Odds ratio; PROs: Patient-reported outcomes; RA: Rheumatoid arthritis; THA: Total hip arthroplasty.

\section{Competing interests}

There are no financial conflicts related directly to this study. JAS has received research grants from Takeda and Savient; and consultant fees from Savient, Takeda, Allergan and Regeneron. DGL has received royalties/speaker fees from Zimmer, has been a paid consultant to Zimmer and has received institutional research funds from DePuy, Stryker and Zimmer. The views expressed in this article are those of the authors and do not necessarily reflect the position or policy of the Department of Veterans Affairs or the United States government.

\section{Authors' contributions}

Study design and protocol: JAS. Revision of study protocol: JAS, and DGL. Data analyses: JAS. Review of analyses and results: JAS, and DGL. Manuscript draft: JAS. Manuscript revision: JAS and DGL. Submission: JAS. Both authors read and approved the final manuscript.

\section{Acknowledgements}

This study was supported by research funds from the Mayo Clinic Orthopedic Surgery research funds, National Institutes of Health (NIH) Clinical Translational Science Award 1 KL2 RR024151-01 (Mayo Clinic Center for Clinical and Translational Research) and the resources and use of facilities at the Birmingham VA Medical Center, Alabama, USA. JAS is also supported by grants from the Agency for Health Quality and Research Center for Education and Research on Therapeutics (CERTs), National Institute of Arthritis, Musculoskeletal and Skin Diseases (NIAMS), National Institute of Aging (NIA) and National Cancer Institute (NCI). The funding agencies played no role in the design, collection, analysis, and interpretation of data; in the writing of the manuscript; or in the decision to submit the manuscript for publication. This study was presented as an oral abstract presentation at the 2012 American College of Rheumatology Annual meeting in Washington, DC in November 2012.

\section{Author details}

${ }^{1}$ Medicine Service and the Center for Surgical Medical Acute Care Research and Transitions (C-SMART), Birmingham VA Medical Center, Birmingham, AL, USA. ${ }^{2}$ Department of Medicine at School of Medicine, and Division of Epidemiology at School of Public Health, University of Alabama, Birmingham, AL, USA. ${ }^{3}$ Department of Orthopedic Surgery, Mayo Clinic College of Medicine, Rochester, MN, USA. ${ }^{4}$ University of Alabama, Faculty Office Tower 805B, 510 20th Street S, Birmingham, AL 35294, USA.

Received: 10 June 2013 Accepted: 30 August 2013

Published: 24 September 2013

\section{References}

1. Learmonth ID, Young C, Rorabeck C: The operation of the century: total hip replacement. Lancet 2007, 370:1508-1519.

2. $\mathrm{Ng} C Y$, Ballantyne JA, Brenkel IJ: Quality of life and functional outcome after primary total hip replacement. A five-year follow-up. J Bone Joint Surg Br 2007, 89:868-873.

3. Rasanen P, Paavolainen P, Sintonen H, Koivisto AM, Blom M, Ryynanen OP, Roine RP: Effectiveness of hip or knee replacement surgery in terms of quality-adjusted life years and costs. Acta Orthop 2007, 78:108-115.

4. Singh JA, Vessely MB, Harmsen WS, Schleck CD, Melton $\amalg$ 3rd, Kurland RL, Berry DJ: A population-based study of trends in the use of total hip and total knee arthroplasty, 1969-2008. Mayo Clin Proc 2010, 85:898-904.

5. Kurtz S, Ong K, Lau E, Mowat F, Halpern M: Projections of primary and revision hip and knee arthroplasty in the United States from 2005 to 2030. J Bone Joint Surg Am 2007, 89:780-785.

6. Cram P, Lu X, Kaboli PJ, Vaughan-Sarrazin MS, Cai X, Wolf BR, Li Y: Clinical characteristics and outcomes of Medicare patients undergoing total hip arthroplasty, 1991-2008. JAMA 2011, 305:1560-1567.

7. Katz JN, Phillips CB, Baron JA, Fossel AH, Mahomed NN, Barrett J, Lingard EA, Harris WH, Poss R, Lew RA, Guadagnoli E, Wright EA, Losina E:
Association of hospital and surgeon volume of total hip replacement with functional status and satisfaction three years following surgery. Arthritis Rheum 2003, 48:560-568.

8. Engh CA, Bobyn JD, Glassman AH: Porous-coated hip replacement. The factors governing bone ingrowth, stress shielding, and clinical results. J Bone Joint Surg Br 1987, 69:45-55.

9. Borstlap M, Zant JL, Van Soesbergen M, Van der Korst JK: Effects of total hip replacement on quality of life in patients with osteoarthritis and in patients with rheumatoid arthritis. Clin Rheumatol 1994, 13:45-50.

10. Kirwan JR, Currey HL, Freeman MA, Snow S, Young PJ: Overall long-term impact of total hip and knee joint replacement surgery on patients with osteoarthritis and rheumatoid arthritis. Br J Rheumatol 1994, 33:357-360.

11. Creighton MG, Callaghan JJ, Olejniczak JP, Johnston RC: Total hip arthroplasty with cement in patients who have rheumatoid arthritis. A minimum tenyear follow-up study. J Bone Joint Surg Am 1998, 80:1439-1446.

12. STROBE Statement: Strengthening the reporting of observational studies in epidemiology. Available at: http://www.strobestatement.org/fileadmin/ Strobe/uploads/checklists/STROBE_checklist_v4_combined.pdf. 2007 [cited 09/06/2012]

13. Rand JA, Ilstrup DM: Survivorship analysis of total knee arthroplasty. Cumulative rates of survival of 9200 total knee arthroplasties. J Bone Joint Surg Am 1991, 73:397-409.

14. Rand JA, Trousdale RT, Ilstrup DM, Harmsen WS: Factors affecting the durability of primary total knee prostheses. J Bone Joint Surg Am 2003, 85-A:259-265.

15. Kavanagh BF, Fitzgerald RH Jr: Clinical and roentgenographic assessment of total hip arthroplasty. A new hip score. Clin Orthop Relat Res 1985, 193:133-140.

16. McGrory BJ, Freiberg AA, Shinar AA, Harris WH: Correlation of measured range of hip motion following total hip arthroplasty and responses to a questionnaire. J Arthroplasty 1996, 11:565-571.

17. McGrory BJ, Morrey BF, Rand JA, Ilstrup DM: Correlation of patient questionnaire responses and physician history in grading clinical outcome following hip and knee arthroplasty. A prospective study of 201 joint arthroplasties. J Arthroplasty 1996, 11:47-57.

18. Andersson G: Hip assessment: a comparison of nine different methods. J Bone Joint Surg Br 1972, 54:621-625.

19. Deyo RA, Cherkin DC, Ciol MA: Adapting a clinical comorbidity index for use with ICD-9-CM administrative databases. J Clin Epidemiol 1992, 45:613-619.

20. Gonzalez Saenz De Tejada M, Escobar A, Herrera C, Garcia L, Aizpuru F, Sarasqueta C: Patient expectations and health-related quality of life outcomes following total joint replacement. Value Health 2010, 13:447-454.

21. Mahomed NN, Liang MH, Cook EF, Daltroy LH, Fortin PR, Fossel AH, Katz JN: The importance of patient expectations in predicting functional outcomes after total joint arthroplasty. J Rheumatol 2002, 29:1273-1279.

22. Wolfe F, Zwillich SH: The long-term outcomes of rheumatoid arthritis: a 23-year prospective, longitudinal study of total joint replacement and its predictors in 1,600 patients with rheumatoid arthritis. Arthritis Rheum 1998, 41:1072-1082.

23. Singh JA, Lewallen DG: Predictors of activity limitation and dependence on walking aids after primary total hip arthroplasty. J Am Geriatr SoC 2010, 58:2387-2393.

24. Singh JA, Lewallen D: Predictors of pain and use of pain medications following primary Total Hip Arthroplasty (THA): 5,707 THAs at 2-years and 3,289 THAs at 5-years. BMC Musculoskelet Disord 2010, 11:90.

25. Harris WH: Traumatic arthritis of the hip after dislocation and acetabular fractures: treatment by mold arthroplasty. An end-result study using a new method of result evaluation. J Bone Joint Surg Am 1969, 51:737-755.

26. Wright JG, Young NL: A comparison of different indices of responsiveness. J Clin Epidemiol 1997, 50:239-246.

27. Hoeksma HL, Van Den Ende CH, Ronday HK, Heering A, Breedveld FC: Comparison of the responsiveness of the Harris Hip Score with generic measures for hip function in osteoarthritis of the hip. Ann Rheum Dis 2003, 62:935-938.

28. Mclnnes IB, Schett G: The pathogenesis of rheumatoid arthritis. N Engl J Med 2011, 365:2205-2219.

29. Ravi B, Escott B, Shah PS, Jenkinson R, Chahal J, Bogoch E, Kreder H, Hawker $\mathrm{G}$ : A systematic review and meta-analysis comparing complications following total joint arthroplasty for rheumatoid arthritis versus for osteoarthritis. Arthritis Rheum 2012, 64:3839-3849. 
30. Hawker GA, Badley EM, Borkhoff CM, Croxford R, Davis AM, Dunn S, Gignac MA, Jaglal SB, Kreder HJ, Sale JE: Which patients are most likely to benefit from total joint arthroplasty? Arthritis Rheum 2013, 65:1243-1252.

31. Bachmeier CJ, March LM, Cross MJ, Lapsley HM, Tribe KL, Courtenay BG, Brooks PM, Arthritis Cost and Outcome Project Group: A comparison of outcomes in osteoarthritis patients undergoing total hip and knee replacement surgery. Osteoarthritis Cartilage 2001, 9:137-146.

32. Harris WH, Sledge CB: Total hip and total knee replacement (2). N Engl J Med 1990, 323:801-807.

33. Harris WH, Sledge CB: Total hip and total knee replacement (1). N Engl J Med 1990, 323:725-731.

34. Johannson HR, Zywiel MG, Marker DR, Jones LC, McGrath MS, Mont MA: Osteonecrosis is not a predictor of poor outcomes in primary total hip arthroplasty: a systematic literature review. Int Orthop 2011, 35:465-473.

35. Rahman WA, Garbuz DS, Masri BA: Total hip arthroplasty in steroidinduced osteonecrosis: early functional and radiological outcomes. Can J Surg 2013, 56:41-46.

36. Singh J, Sloan JA, Johanson NA: Challenges with health-related quality of life assessment in arthroplasty patients: problems and solutions. J Am Acad Orthop Surg 2010, 18:72-82.

37. Asch DA, Jedrziewski MK, Christakis NA: Response rates to mail surveys published in medical journals. J Clin Epidemiol 1997, 50:1129-1136.

38. Quintana JM, Escobar A, Aguirre U, Lafuente I, Arenaza JC: Predictors of health-related quality-of-life change after total hip arthroplasty. Clin Orthop Relat Res 2009, 467:2886-2894

doi:10.1186/1741-7015-11-210

Cite this article as: Singh and Lewallen: Patients with osteoarthritis and avascular necrosis have better functional outcomes and those with avascular necrosis worse pain outcomes compared to rheumatoid arthritis after primary hip arthroplasty: a cohort study. BMC Medicine $201311: 210$

\section{Submit your next manuscript to BioMed Central and take full advantage of:}

- Convenient online submission

- Thorough peer review

- No space constraints or color figure charges

- Immediate publication on acceptance

- Inclusion in PubMed, CAS, Scopus and Google Scholar

- Research which is freely available for redistribution 